\title{
Sustainable Urban Mobility Plan for Municipality of Veles 2019-2030
}

\author{
Jovan Hristoski, ${ }^{a}$ Goran Jovanovic, ${ }^{b}$, Andon Petrovski ${ }^{c}$, Olivera Petrovska ${ }^{a}$ \\ a Faculty of Technical Sciences, University Mother Teresa-Skopje, N. Macedonia \\ ${ }^{b}$ APPIA DOO Ljubljana, Ljubljana, Slovenia \\ c 24 ING DOOEL Bitola, N. Macedonia
}

\begin{tabular}{|c|c|}
\hline ARTICLE INFO & A B S T R A C T \\
\hline $\begin{array}{l}\text { DOI: } 10.31075 / \text { PIS.66.01.04 } \\
\text { Professional paper } \\
\text { Received: } 27.12 .2019 \\
\text { Accepted: } 30.01 .2020 \\
\text { Corresponding author: } \\
\text { jani.hristoski@unt.edu.mk } \\
\text { Keywords: } \\
\text { Sustainable urban mobility plan } \\
\text { Traffic planning } \\
\text { Traffic studies }\end{array}$ & $\begin{array}{l}\text { The central element of the integrative traffic planning is Sustainable urban } \\
\text { mobility plan (SUMP). It is based on EU documents and guidelines set by } \\
\text { European commission. Integrated traffic planning does not reject, but upgrades } \\
\text { current planning practices and it has a long-term and strategic vision striving } \\
\text { towards sustainable mobility. SUMP of the Municipality of Veles is aiming } \\
\text { towards an attractive public passenger transport, branched network of safe } \\
\text { cycling routes and good conditions for pedestrians. It focuses on city center as } \\
\text { a regulated, attractive, accessible and safe urban space. This paper } \\
\text { summarized the sustainable measures and projects that are planned for } \\
\text { implementation and have impact on the city and its inhabitants. }\end{array}$ \\
\hline
\end{tabular}

\section{INTRODUCTION}

Integrative traffic planning is a new way of planning that originates from experiences and good practices of many European cities and regions that have been working on successfully implementing its key principles. Its main objective is to reduce environment related burden caused by transport system and contributing to establishment of a sustainable, livable, attractive, accessible and healthy environment.

The central element of the integrative traffic planning is Sustainable urban mobility plan (SUMP). It is based on EU documents and guidelines set by European commission. SUMP offers possibility for transition from classic to modern and comprehensive traffic planning. Integrated traffic planning does not reject, but upgrades current planning practices and it has a longterm and strategic vision striving towards sustainable mobility.

SUMP is a document in which the Municipality of Veles drafted a set of measures which will help achieve a shift toward more sustainable transport modes and higher quality of living. It is aiming towards an attractive public passenger transport, branched network of safe cycling routes and good conditions for

* This paper was presented at the 7th International Conference „Towards a Humane City", 6-7th Decembar 2019. in Novi Sad, Republic of Serbia. pedestrians. It focuses on city center as a regulated, attractive, accessible and safe urban space. Municipality of Veles will use the proposed document to upgrade existing spatial acts and strategic documents, leading to more comprehensive planning and inclusion of sustainable strategies into planning act.

\section{SUSTAINABLE URBAN MOBILITY PLAN (SUMP)}

A Sustainable urban mobility plan (SUMP) is a document that incorporates and upgrades existing strategic documents of municipality. It is a new way of thinking and planning that represents a step towards more sustainable traffic planning in the region - in line with modern guidelines and recommendations of the European commission.

SUMP is comprehensive integrated traffic planning that upgrades current planning practices and it has a long-term and strategic vision striving towards sustainable mobility. Sustainable urban mobility plan is a result of the participation of an expert group on transport planning, local authorities and affected social groups. Local institutions and citizens played an important role in the creation of the document as their values and proposals serve as a basis for proposed measure packages. 
The planning process consists of eleven main steps made up of 32 activities. They should be taken as part of a regular planning cycle in the sense of a continuous improvement process.

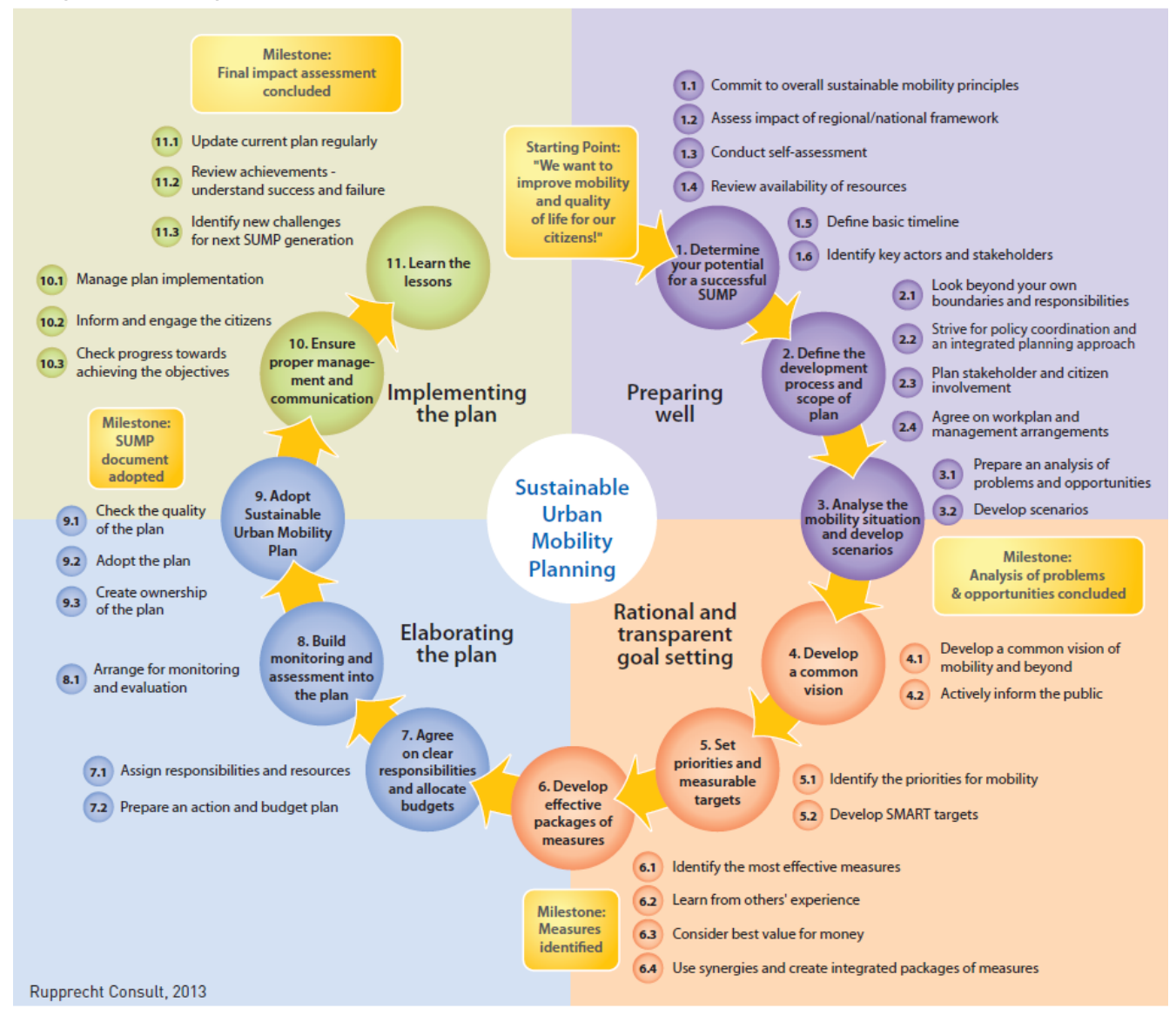

Figure 1. Planning cycle for a sustainable urban mobility plan,

Source: Guidelines, 2014, https://www.eltis.org/guidelines/sump-guidelines

\section{SUMP OF MUNICIPALITY OF VELES}

The document reflects the planned development of city of Veles and is prepared in line with existing spatial and urban planning documents. Individual measures can be implemented and coordinated with existing and incorporated in future planning documents. Infrastructural projects will be implemented in connection with soft measures, aimed at reducing demand for private motorized transport and incentivizing other more sustainable modes of transport, strengthening each other's impacts.

In course of preparation of the document, public consultations regarding challenges and opportunities that municipality faces were held with local authorities and interest groups. The participants presented their aspects and views on the existing situation in the municipality while their comments were evaluated and utilized in preparation of proposed vision and measures.

\subsection{Challenges}

An analysis of the current situation in the Municipality of Veles was made in the framework of the development of the Sustainable Urban Mobility Plan. Identification of current situation represents an important step in achieving sustainable mobility in the municipality of Veles.

UNSUSTAINABLE TRAVEL HABITS - In the development of Sustainable Urban Mobility Plan, a questionnaire was prepared for the general population of municipality. The survey of 4200 inhabitants (almost $10 \%$ of population) examines travel habits and the opinion of citizens on the current situation in the field of transport. Majority of population (53\%) uses car as primary means of transportation. Other more sustainable means of transport are used by $47 \%$ of respondents of which $39 \%$ are pedestrians, $7 \%$ use public transport and cycling only $1 \%$. 
LACK OF INTEGRATED TRANSPORT PLANNING Traffic planning investments were oriented in motor traffic and in most of the cases were carried out within the framework regulation of motor traffic.
REDUCED ACCESSIBILITY FOR PEDESTRIANS While the city center is well equipped with pedestrian infrastructure the existing sidewalks are in many cases deteriorated, their surfaces are in bad condition and there are frequent conflicts in relation to other traffic modes (parking, crosswalks) in addition the infrastructure is inadequately equipped for access of sensory and physically impaired citizens.
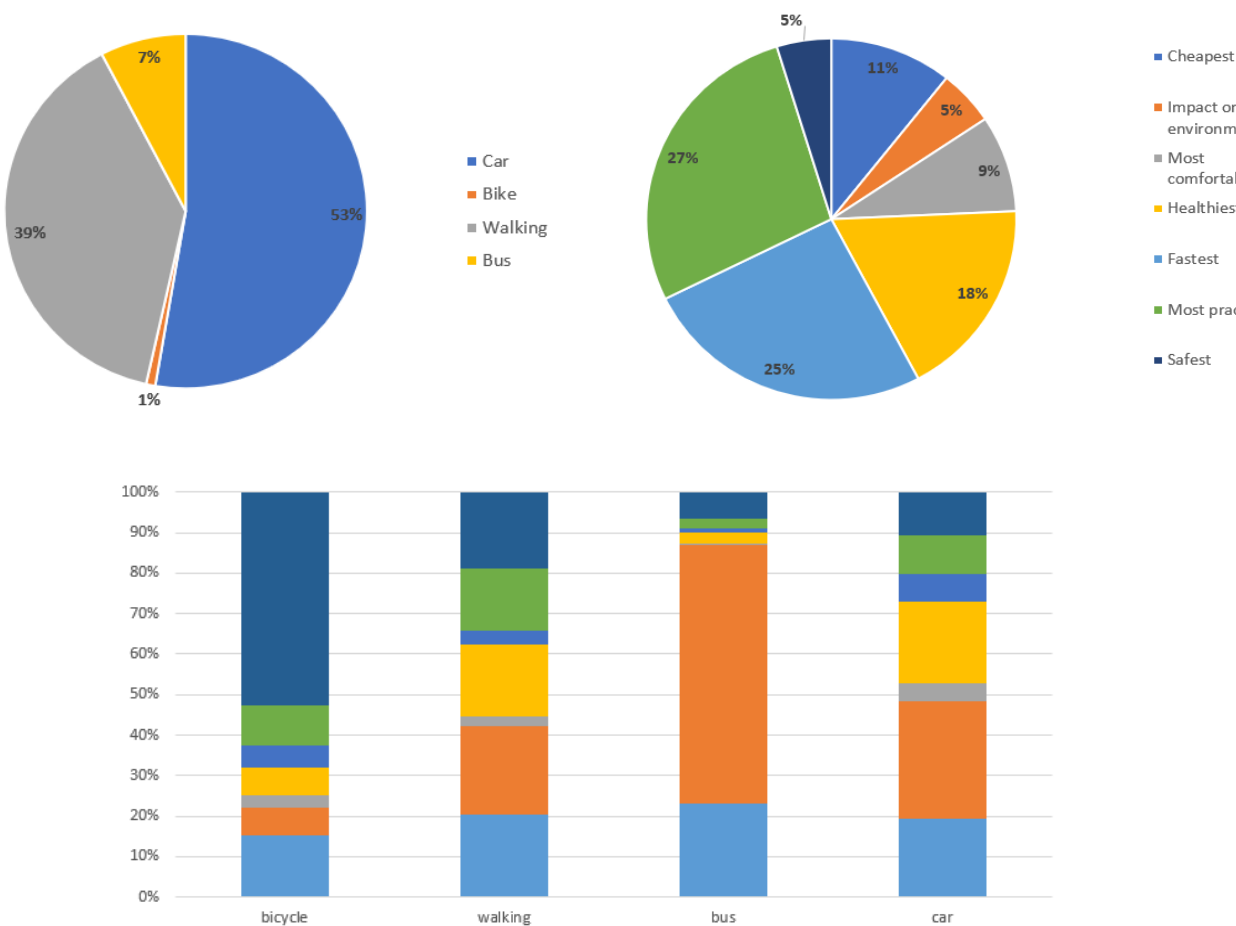

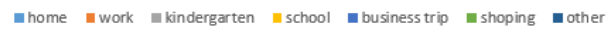

Figure 2. Modal split and purpose of trip by individual means of transport

UNSUITABLE CONDITIONS FOR CYCLISTS Despite many advantages of cycling there is almost no cyclist infrastructure available in the Municipality of Veles. In most of regional and local roads the cyclist is a subordinate position compared to the motor traffic.

\section{UNOPTIMISED PUBLIC PASSENGER TRANSPORT}

- Public passenger transport has been largely neglected in urban planning after the increase in motorization and could not flexibly follow personal car use. Only $7 \%$ of citizens use public transport as their main mode of transport for daily trips. More than half of respondents never use public transport, and $31 \%$ use it rarely.
HIGH DENSITY OF MOTOR TRAFFIC IN CITY CENTRE - City of Veles is located on the X European corridor. The consequence of heavy traffic load (especially freight traffic) is a decrease in road safety and quality of life due to noise, vibrations and emissions. Illegal parking occurs on sidewalks, bus stops, traffic lanes and greenery and hinders accessibility for pedestrians (especially for people with disabilities) and cyclists and additionally decreases the attractiveness of the area. 


\subsection{Vision and objectives}

The Municipality of Veles has the potential for successful future development of transport and the vision has been established as: "The City of Veles will implement people-centric and environmentally friendly transport policy. Integrated and innovative approaches will encourage the establishment highest level of road safety and an environment for high quality of life and benefits local economy and tourism. ,

Strategic objectives proposed in this document strive for liveable urban environment and safe and accessible transport network based on sustainable planning principles:

- Greater accessibility for all population groups for a higher quality of life in the municipality,

- Establishing greater integration, competitiveness and accessibility among all transportation modes, with an emphasis on existing public passenger transport,
- Establishing a smart parking policy that will relieve the city centre of vehicular traffic,

- To halve the number of accidents with serious injuries and to achieve zero mortality on the roads in the municipality,

- Promotion of sustainable travel methods for all groups of citizens, with an emphasis on young people.

\subsection{Scenarios and transportation model}

Within the framework of the working group and cooperation with stakeholders, four scenarios for the development of the transport network in the Municipality were designed. For each scenario, measures were identified that are integrated and verified using traffic modeling tools for the period 2019 to 2030 year.

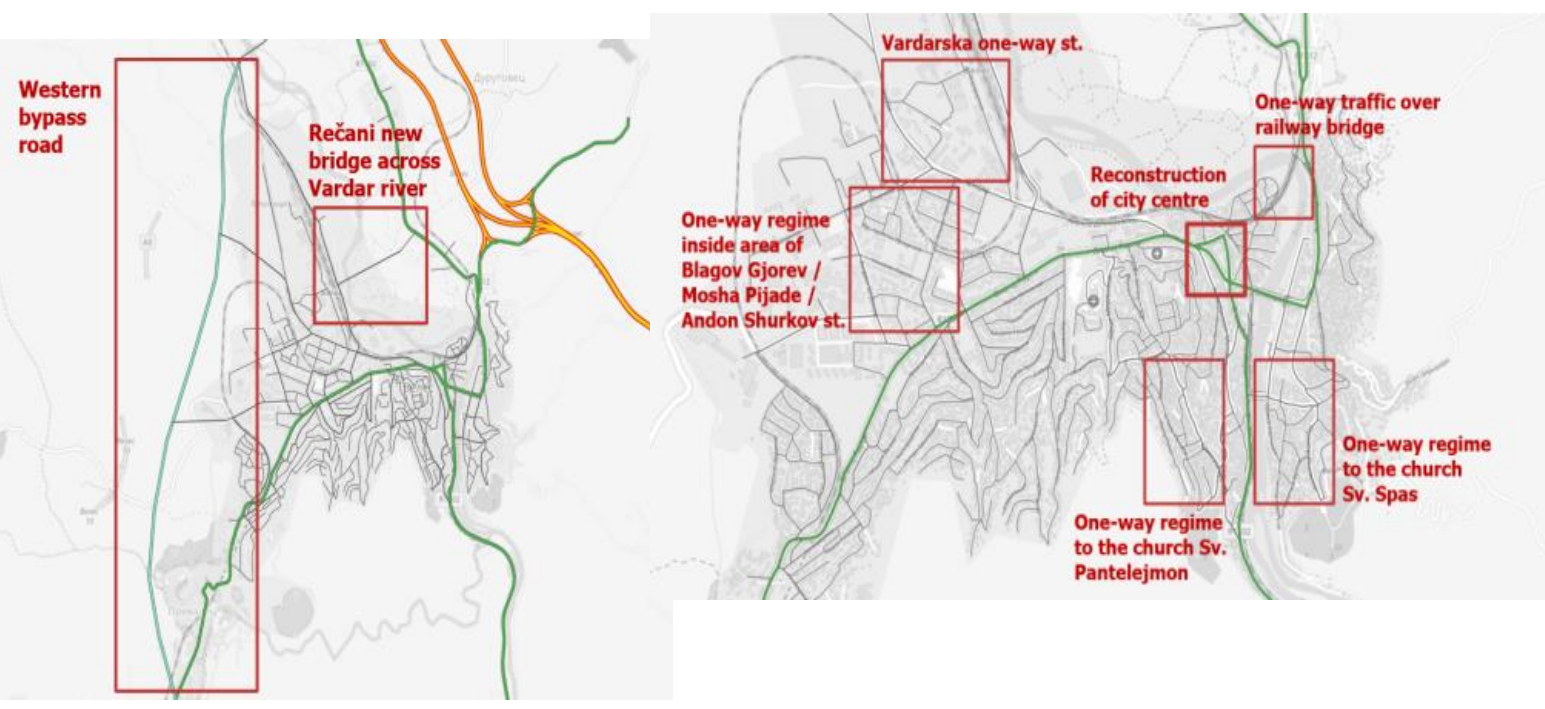

Figure 3. Different scenarios and measures for development of transport network
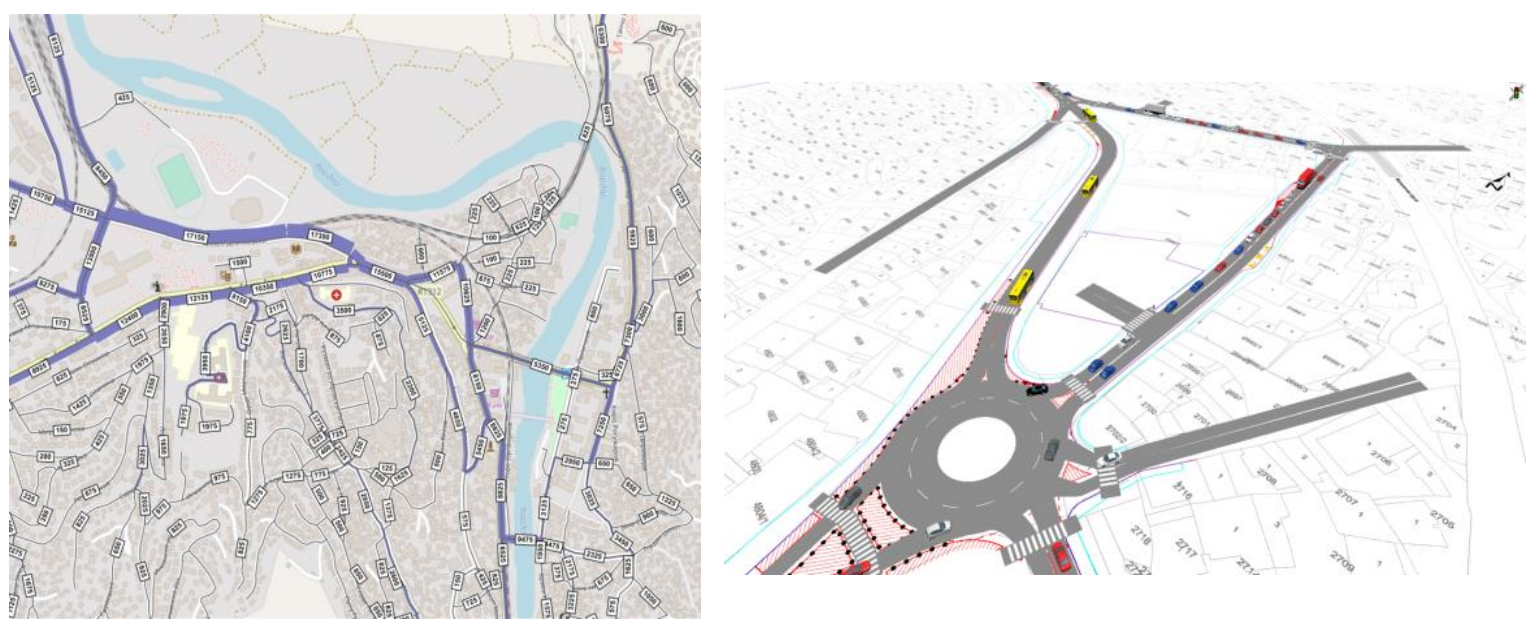

Figure 4. Transportation model and traffic simulation of city center 


\section{SUMP MEASURES}

Sustainable urban mobility plan of the Municipality of Veles is based on five key areas of action. The objectives have been defined for five intervention areas and a set of measures was assigned to each of them. Measures include infrastructural projects and soft measures which will be developed and implemented and represent tools for implementation of the Plan. By realizing goals in complementary strategic areas, the vision of an intelligently organized city in the field of transport can be achieved.

Table 1. SUMP measures for Veles

\begin{tabular}{|l|l|}
\hline \multicolumn{2}{|c|}{ Measure - EFFECTIVE GOVERNANCE } \\
\hline G1 & Acceptance, commissioning, revision and reform of the SUMP \\
G2 & Personnel training in field of sustainable mobility and its \\
G3 & implementation in planning processes \\
G4 & Preparing a balanced budget \\
G5 & Promotic survey on travel habits \\
\hline Measure - PROMOInOTION OF WALKING AS IMPORTANT TRANSPORT \\
MODE \\
\hline W1 & Pedestrian areas \\
W2 & Implementation of safe pedestrian crossings \\
W3 & Building a new and improving the current infrastructure \\
W4 & Adaptation of infrastructure for people mobility impairments \\
W5 & Safe school routes documents \\
W6 & Promotion of walking \\
\hline Measure - BICYCLING IMPROVEMENT \\
\hline C1 & Arrangement of cycling along the main road across the city \\
C2 & Regulated traffic signalling on long distance cycling routes \\
C3 & Construction of the bicycle network - multipurpose paths \\
C4 & Parking lots for short-term and long-term parking of bicycles \\
C5 & Bike rental system \\
C6 & Promotion of cycling \\
\hline Measure - PUBLIC TRANSPORT DEVELOPMENT \\
\hline P1 & Improvement of existing bus stops and arranging safe access for \\
P2 & Public transport users \\
P3 & New bus service lines \\
P4 & Reassignment of main bus station into intermodal transport centre \\
P5 & Public transport on-demand \\
P6 & Promotional campaigns to promote the use of public passenger \\
\hline Measure - traffic flow optimization \\
\hline M1 & Implementation of a parking policy \\
M2 & Regulation of one-way roads \\
M3 & Implementation of P+R system \\
M4 & Analysis and registry of accident blackspots \\
M5 & Expanding the network of charging stations \\
M6 & Extension of the road network \\
M7 & New environmentally friendly vehicles \\
M8 & Urban consolidation centre \\
\hline
\end{tabular}

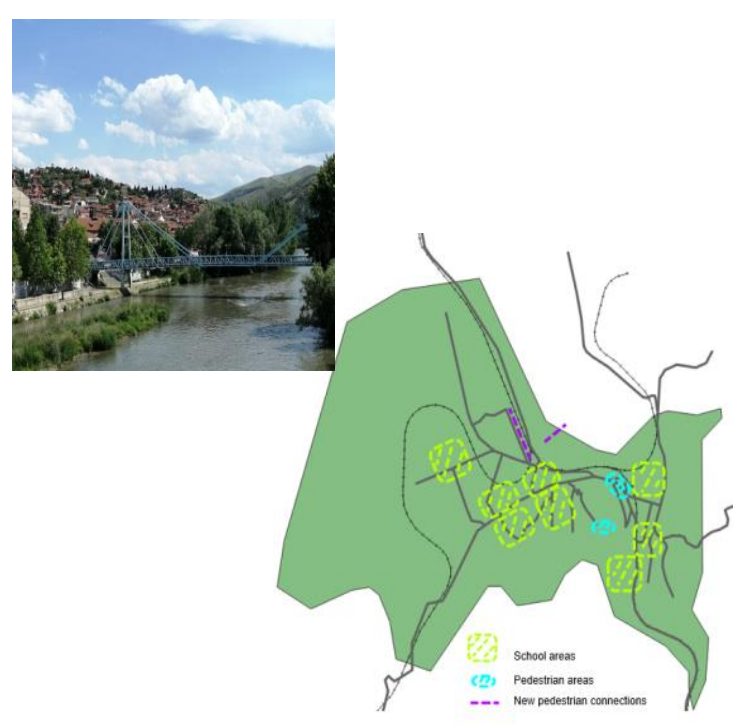

Figure 5. SUMP mesures for Veles

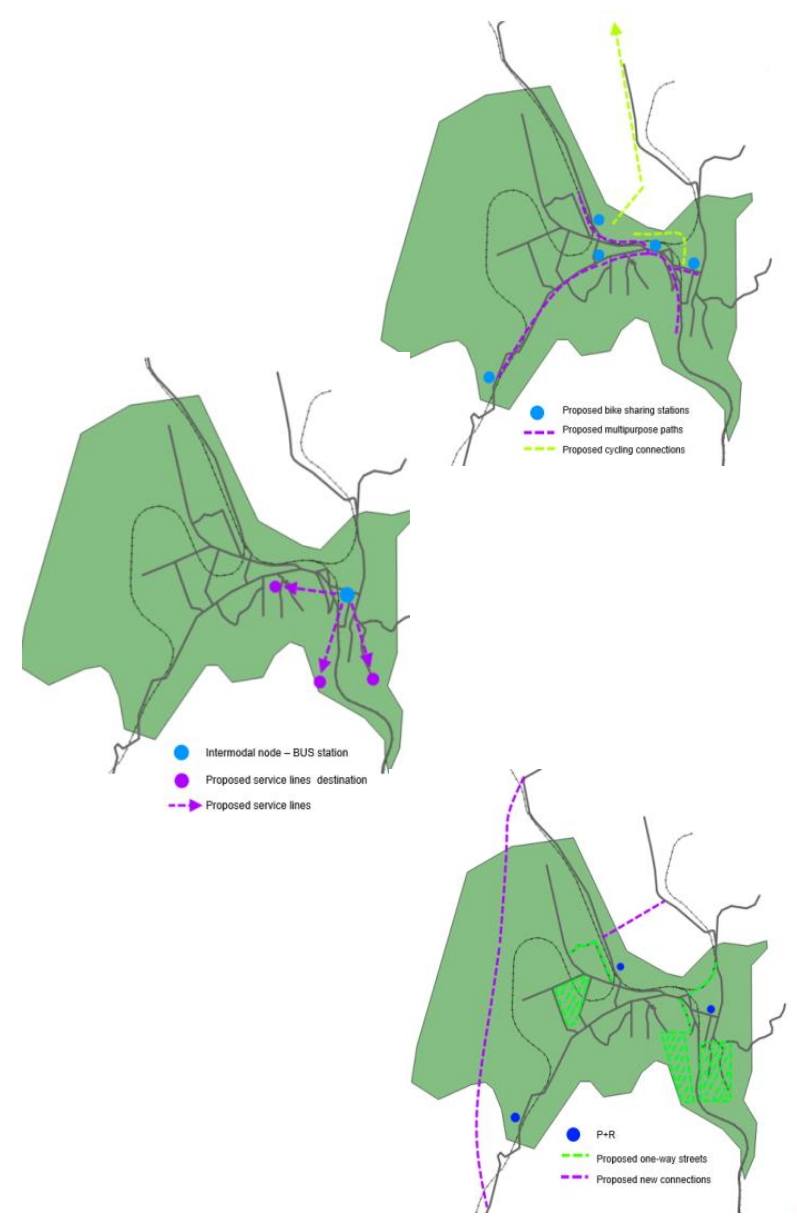

Figure 6. SUMP measures for Veles (cont.) 


\section{CONCLUSION}

Measures and projects that have impact on the city of Veles and its inhabitants are planned and will be implemented in line with the framework proposed in this document. Strategic transport development practices are in synergy with urban development of the area and give priority to increasing quality of life by promotion and implementation of sustainable measures.

Adoption of the SUMP of Municipality of Veles does not mean its conclusion, but a transition to its implementation.

The planning process will not come to an end with adoption of Sustainable urban mobility plan of Municipality of Veles. The process will continue with gradual preparation and implementation of proposed measures. The monitoring system is set to evaluate implemented measures and their contribution to set strategic goals. Integrated traffic planning is a cyclic process and should be considered as a continuous improvement process with regular reassessments and renewals.

\section{References}

[1] May, A. (2016). EU project CH4LLENGE: Measure selection manual - Selecting the most effective packages of measures for Sustainable Urban Mobility Plans. Brussels.

[2] Gühnemann, A. (2016), EU project CH4LLENGE: Monitoring and Evaluation Manual - Assessing the impact of measures and evaluating mobility planning processes. Brussels.

[3] Rupprecht Consult (editor) (2019). Guidelines for Developing and Implementing a Sustainable Urban Mobility Plan, Second edition. Cologne.

[4] Municipality of Veles (2008). General urban plan for City of Veles. Veles.

[5] European Commission, (2007). GREEN PAPER Towards a new culture for urban mobility. Brussels.

[6] European Commission (2011). WHITE PAPER Roadmap to a single European Transport Area Towards a competitive and resource efficient transport system. Brussels. 